\title{
Reconsidering Asymmetric Regulation of Korean Television Industry
}

\author{
Joon-Ho Lee1)
}

\begin{abstract}
This study intends to explore the current policy and legal issues regarding Korean broadcasting media industries and markets, and to propose theoretically and practically applicable alternatives that may provide solutions for more effective and fair competition among the media. Starting in 1980s and 1995, both US and Korean asymmetric regulatory policies of electronic media industries have been facing challenges since 2000 s and 2010s, respectively, because the regulation lacks rationale and effectiveness in coordinating competitions among broadcasting media. After reviewing and analyzing 7 current critical issues in Korean broadcasting market regulation and policy, 4 points of alternatives are proposed. In conclusion, as the practical issues came from the different views on TV contents, services, and market, Korean regulatory authorities should establish more clear legislative principle about public interest, universal service, characteristics of TV content, and methods for TV market deployment.
\end{abstract}

Keywords : Asymmetric Regulation, Broadcasting Industry, Competition, Media Law, Public Interest

\section{Introduction - Intent of the Study}

One of the main current issues regarding Korean broadcasting media industries, in which a trend of diversification and digitalization has been increasingly dominant, has been the establishment and revision of the regulation system for fair and effective competition among the media. Currently the Korean broadcasting industry is regulated by Broadcasting Law and related policy that focused on balanced competition among media by securing and encouraging fair competition, diversity, and audiences' (viewers') welfare. This policy has been designed to introduce new and diverse digital television media and their services into the market, and to encourage the industry to gain synergies by sustaining coexistence and creating a complementary nature for the various digital media.

However, the current Korean policy and legal regulation assign a restrictive duty called

Received(July 16, 2018), Review Result(1st: July 31, 2018, 2nd: August 27, 2018), Accepted(September 10, 2018)

1) (Professor) Department of Communication \& Media, Dong-eui Univ., Eomgwangno 176, Busanjin-gu, Busan 47340, Korea

e-mail: joonlee@deu.ac.kr 
'public interest' to traditional terrestrial media although non-terrestrial, pay (subscription) TV media (cable TV, Satellite TV, IPTV, etc.) can pursue their profitable non-public interest from their content and advertising, thus enjoying a higher level of freedom. This regulatory point is called 'asymmetric regulation,' by which the prior and dominant participants in the market (terrestrial TV) are severely regulated whereas the new and non-dominant counterparts are less regulated. It has been criticized by a number of mass media researchers as well as terrestrial broadcasters. They argue that the asymmetric regulation is not actually balanced but rather it is reverse discrimination because the conventional broadcasters then suffer from a decrease in ratings, advertising revenue, profits, negative social effects and a loss of the market-dominant status[1].

This study intends to explore the current policy and legal issues regarding Korean broadcast media industries and markets and to propose theoretically and practically applicable alternatives that may provide solutions that are more effective and fair competition among the media. In order to do this, the rationale and history of asymmetric media regulation are reviewed, several related issues are discussed, and possible alternatives are proposed.

\section{Rationales and History of Asymmetric Regulation of Media}

\subsection{Theories and Rationales}

Generally, many governments in the world intend to protect or promote free and fair competition by regulating specific economic agents. In accordance with this principle, the economic order of many countries is based on respect for the freedom and creative initiative of enterprises and individuals in economic affairs[2]. The state may regulate and coordinate economic affairs in order to maintain balanced growth and stability of the national economy, to ensure proper distribution of domestic income, to reduce domination of the market, and to prevent abuse of economic power, and to democratize the national economy by attaining harmony among the economic agents[3].

In broadcasting and telecommunication industries, many capitalist countries' government authorities impose different types and levels of regulation systems on each type of enterprise if their impact or share in the market is not the same or similar[4]. Asymmetric regulation is a regulation system that applies stricter regulation to market dominant operators such as terrestrial broadcasters, KT(Korean Telecom), and AT\&T(American Telephone \& Telegraph) whereas it gives benefits or applies weaker regulation to newcomers in the market, such as 
pay TV operators and smaller telecommunication enterprises.

\subsection{History}

The origin of asymmetric media regulation goes back in time to the 1980s when the FCC (Federal Communications Commission), and the American regulating authorities in telecommunications, began to regulate rates (tools) and ownership of AT\&T which had monopolistic power in local industry and satellite operators. Instead the authority gave more freedom to cable TV companies. The FCC regulation in the 1980s was mainly based on the purpose of lessening the economic power of dominant enterprises (AT\&T, Satellites, terrestrial TV) and of strengthening the competing ability of late-comers (Sprint, MCI, cable TV) in electronic media industries[5]. Later, as results of early asymmetric regulation, newcomers' competitiveness and market share increased dramatically until the early 1990s. The FCC reduced the strictness of its regulation level in the telecommunications industry and applied reversed asymmetric regulation in the television industry. In the 2000s, US electronic media industries were under mostly symmetric and post regulations, by which barriers to entry and competition in the market were almost free. At that time disputes between competitors were dealt with in courts[6].

Korean asymmetric regulatory policy began in 1995, when a real competition environment was created by the Korean government when they launched a multichannel TV service (cable TV) and a series of local independent commercial broadcasting stations nationwide. This policy and a legislative change aimed to coordinate substitutional and complementary relations among the media. They also intended to promote diversity and fair competition in the broadcasting industry (see Fig. 1). This policy is called 'media policy for balanced development'[7].

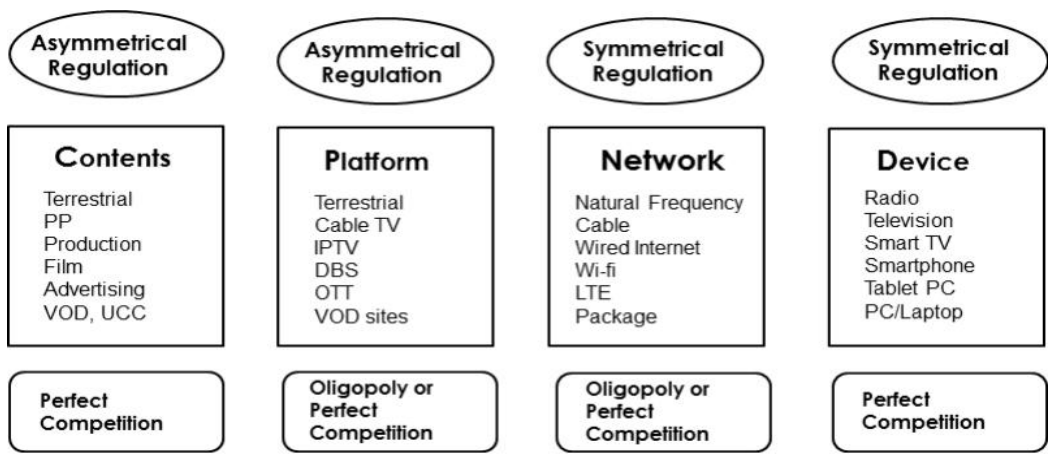

[Fig. 1] The Ecosystem, Competition, and Regulation of Korean Broadcasting Media Industry 
A series of regulating laws were introduced and revised. They have prohibited terrestrial broadcasters from programming interstitial advertising, 24-hour casting, increasing viewers' subscription fees and MMS services (a technology for dividing a TV channel into 2 5 separate channels by compressing digital TV signals). The laws also restricted the broadcasters' freedom of selecting program genres and sources. Similarly to the former US experience, terrestrial TV stations' ratings, share, advertising, and programming revenues shrunk persistently throughout 2000s 2010s (see [Table 1]), whereas many multichannel, pay TV operators achieved their business goals and surpassed their elder competitors. Regarding this fact, a number of petitions and debates concerning the reconsideration of the regulative system from asymmetric to symmetric have been raised.

[Table 1] Revenues of Korean TV Broadcasters[8]

(Unit: 0.1 bil. Won)

\begin{tabular}{|c|c|c|c|c|c|c|c|c|c|}
\hline \multirow[b]{2}{*}{ Broadcasters } & \multirow[b]{2}{*}{2012} & \multirow[b]{2}{*}{2013} & \multirow[b]{2}{*}{2014} & \multirow[b]{2}{*}{2015} & \multirow[b]{2}{*}{2016} & \multirow[b]{2}{*}{ share } & \multicolumn{2}{|c|}{ '15 '16 } & \multirow{2}{*}{$\begin{array}{c}\text { '12 '16 } \\
\text { average } \\
\text { growth } \\
\text { rate }\end{array}$} \\
\hline & & & & & & & growth & $\begin{array}{l}\text { growth } \\
\text { rate }\end{array}$ & \\
\hline KBS & 15,040 & 14,855 & 14,833 & 15,324 & 14,714 & $36.8 \%$ & -610 & $-4.0 \%$ & $-0.5 \%$ \\
\hline MBC & 7,836 & 8,051 & 7,966 & 8,434 & 8,294 & $20.7 \%$ & -140 & $-1.7 \%$ & $1.4 \%$ \\
\hline SBS & 7,357 & 6,901 & 7,775 & 7,517 & 7,775 & $19.4 \%$ & 257 & $3.4 \%$ & $1.4 \%$ \\
\hline EBS & 1,534 & 1,632 & 1,699 & 1,714 & 1,673 & $4.2 \%$ & -41 & $-2.4 \%$ & $2.2 \%$ \\
\hline Local MBC & 3,526 & 3,265 & 3,308 & 3,392 & 2,998 & $7.5 \%$ & -393 & $-11.6 \%$ & $-4.0 \%$ \\
\hline Local Independent & 2,578 & 2,443 & 2,398 & 2,488 & 2,262 & $5.7 \%$ & -226 & $-9.1 \%$ & $-3.2 \%$ \\
\hline Other & 1,700 & 1,816 & 2,070 & 2,138 & 2,272 & $5.7 \%$ & 134 & $6.3 \%$ & $7.5 \%$ \\
\hline Total (Terrestrial TV) & 39,572 & 38,963 & 40,049 & 41,007 & 39,987 & $100 \%$ & $-1,019$ & $-2.5 \%$ & $0.3 \%$ \\
\hline Total (Pay TV Platforms) & 28,516 & 29,249 & 43,867 & 477,174 & 51,615 & $100 \%$ & 4,450 & $9.4 \%$ & $16.4 \%$ \\
\hline
\end{tabular}

\section{Current Issues and Debates}

The following questions have been suggested as a summary of issues and debates about the usefulness and fairness of the Korean broadcasting policy and laws[9-11].

1) Which is the dominant market operator?

2) Are free and universal services for public interest possible?

3) Is interstitial advertising be desirable on terrestrial TV?

4) Are the (re)transmission fees for terrestrial TV programs reasonable?

5) Are there unacceptable benefits for general programming pay TV channels (jongpyeon)?

6) Is it necessary to regulate the proportion of TV shows from outsourcing productions?

7) Is it reasonable to apply asymmetric regulation to pay TV platforms? 
First, as shown in Table 1, the revenues of Korean terrestrial broadcast stations' have decreased lately but those of pay TV platforms have increased mainly because of the differentiation in advertising and programming regulations. Thus, it is not clear that we should designate a dominant TV market player which enjoys monopoly power.

Secondly, as mentioned above, terrestrial TV channels, especially KBS1, EBS, and local affiliates of KBS and $\mathrm{MBC}$, are not free from performing public roles with restraint budgets. Nevertheless, the concept and examples of public interest are not defined satisfactorily in Korean Broadcasting Law[12]. Regardless, most terrestrial channels are required to send signals containing public interest announcements to viewers nearly free of charge - a monthly terrestrial subscription fee of $\Psi 2,500$ is imposed on every TV household's electricity bill.

Third, the KBS1 channel is traditionally prohibited from sending advertising to viewers, and other terrestrial channels can get advertising revenues strictly to a limited extent. Compared to pay channels, interstitial advertising (ads intercepting a single TV program) is prohibited except for sports and long-time event programs. This results in a decrease of advertising effects and revenues for terrestrial TV channels.

Fourth, as there are only 6 terrestrial channels and most of them are not clearly received through the air by home viewers, pay TV platforms (cable TV SOs, satellite, and IPTV platforms) play an important role in retransmitting terrestrial TV signals and in providing viewers with information and entertainment. The terrestrial broadcasters and pay TV platforms make contracts using pay retransmission fees. Very frequently negotiating and contracting processes are very complicated, and result in legal suits because terrestrial broadcasters aim to collect higher unit fees to compensate for their short of operating costs.

Fifth, several pay channels with general programming (jongpyeon) were launched in 2011. They enjoyed a freedom of programming variety and advertising revenues. They could produce and transmit all kinds of TV contents besides news programs with much advertising revenue. It is thought that the government gave asymmetric benefits to these channels.

Sixth, Korean regulative authorities imposed compulsory rules that every terrestrial TV channel must send a minimum proportions of programs made by outsourcing (independent) productions. The problem is that the degree of proportions are inconsistently imposed from station to station. These rules, beginning in 1991, have tended to generate conflicts between national stations and independent producers.

Finally, an asymmetric regulation applies not only between terrestrial and pay TV but among pay TV platforms because the regulatory laws are separately established based on the difference in transmitting methods of platforms (cable, satellite, and the Internet) even though they 
provide almost the same or similar channels, contents, and programming. Korean media laws are not unified but separately applied according to the platform basis especially in regulating the ownership and market share. This regulatory policy has been criticized as creating a very confusing and unfair media competition environment.

\section{Applicable Policy Alternatives}

Based on the exploration of the seven policy issues above, some limitations and a lack of usefulness and fairness in the current asymmetric regulation were found and applicable policy alternatives are suggested as follows.

First, one of the main factors generating the limitation of asymmetric regulation has been neglecting the similarity and uniformity of various TV platforms. Viewers perceive that most TV services and contents are the same or similar, but government policy has focused on different aspects of them, such as networks and business models. In this respect, an alternative policy reconsideration with the 'principle of same-product/market, same-regulation' is required.

Second, theoretically and practically asymmetric regulation of the industry or the market should be temporarily enacted until the market situation becomes effectively competitive and mature[13]. Since the revenues and profits of terrestrial TV, representing its competitiveness, have been shrinking and yearly gain deficits for pay TV grows and gain more and more revenue and profit, terrestrial TV broadcasters have experienced an unprecedented financial crisis and have lost their influence on public opinion to a great extent. This fact means there will be much less potential for getting public interest from terrestrial TV as well as from pay TV.

Third, more specifically, it will be better for Korean regulative authorities to promote activation of terrestrial TV by providing it with some benefits in terms of financial and technical support, advertising, programming, and incentives for public service. In other words, the competitiveness of terrestrial TV and the balance of economic and social power of each TV medium need to be encouraged. Korean media regulation systems need to support and help the traditional TV signals directly sent to viewers, and then to loosen the responsibility (duties) of the terrestrial TV in terms of advertising and programming, while checking if there are blind spots in pay TV regulation system.

Finally, sophisticated regulatory considerations and revisions are needed that reflect the current competitive situation among media especially in the aspects of redefining products (TV contents) and of the dominance level in the market. Above all, a new regulation should 
compare potential advantages of free, universal services of terrestrial TV and profits from subscription services of pay TV, and try hard to balance them. Then each medium's revenue, profit, and consumer preference and satisfaction need to be measured periodically in order to define which medium is dominant or which medium deserves these benefits.

\section{Conclusion}

Facing an age of digital revolution and the $4^{\text {th }}$ industrial revolution, broadcast signals will be transmitted on a barrier-free basis throughout various telecommunication networks. From the viewers' perspective, the TV signals and contents from any sources of broadcasters look almost the same competing products, while looking different from a legal and economic perspective. Although governmental regulation has tried to promote terrestrial TV's public interest and pay TV's financial profits, the public does not perceive that terrestrial TV serve enough public interest and that pay TV needs more profits. Also, they do not think that the products from both TV services have different economic value, and they are not interested in which is dominant operator or deserves more severe regulation and control. Therefore, it is necessary for the government to facilitate more convenient circumstances in which the terrestrial and pay TV runners play an inherent social and economic role in order to serve their loyal viewers.

Based on viewer conceptions and the current market situation discussed above, Korean regulatory authorities should accept most policy alternatives that are proposed. Before doing this, they need to establish a legislative principle about public interest, universal services, the characteristics of TV contents, and more specific and accurate methods for deploying and measuring TV market environments.

\section{References}

[1] Y. Chung, Korea Broadcasting Policy: Legal Analysis and Discussion, Journal of Broadcasting Research, (2011), Vol.75, pp.58-86.

[2] Y. Kim and J. Jung, Asymmetric Regulation in the Broadcasting Industry, Korean Journal of Broadcasting and Telecommunication Studies, (2010), Vol.24, No.5, pp.47-89.

[3] I. S. Jung, Structure of Broadcasting Industry, Communication Books, Seoul, (2013)

[4] K. J. Park and S. K. Choi, Evaluating the Balanced Media Development as a Broadcasting Policy in Korea, 
Korean Journal of Broadcasting and Telecommunication Studies, (2008), Vol.22, No.4, pp.49-90.

[5] M. C. Choi, Asymmetric Regulation of FCC and Fair Competition, Proceedings of Annual Convention of the Institute of Electronics and Information Engineers, (2000), November 10; Seoul, Korea

[6] M. Katz, J. Orszag, and T. Sullivan, An Economic Analysis of Consumer Harm from the Current Retransmission Consent Regime, National Cable \& Telecommunications Association, USA, (2009)

[7] J. H. Lee, Rationale and Limitation of Asymmetric Regulation of Broadcast Industry, Proceedings of Annual Convention of Korea Speech, Media and Communication Association, (2017), October 28; Seongnam, Korea

[8] Reports of Fact-Finding Survey, Ministry of Science, ICT and Future Planning and Korea Communications Commission, Seoul, (2014, 2015, 2016)

[9] W. J. Jung and P. W. Jung, Pay TV Regulation in the Smart Age : Overview and Future Subjects, Journal of Law and Economic Regulation, (2014), Vol.7, No.2, pp.56-73.

[10] J. H. Lee, Rationale and Limitation of Asymmetric Regulation of Broadcast Industry, Proceedings of Annual Convention of Korea Speech, Media and Communication Association, (2017), October 28; Seongnam, Korea

[11] S. Y. Lee, The Study of Issues and Improvement Plan Regarding Legislation of Terrestrial Broadcasting Retransmission: focused on Broadcasting Carriage Order, Mandatory Mediation and Adjudication. Journal of Law and Economic Regulation, (2015), Vol.8, No.1, pp.128-145.

[12] S. O. Yun, How to Define Public Interests of Broadcasting: Research on the Theory and Practice for Establishing Policy Objectives, (2013), Vol.12, No.1, pp.143-183.

[13] W. S. Hong, Horizontal Media Environment and Symmetric Media Regulation: Focusing on Terrestrial Broadcasting, Broadcasting Culture, (2017), Vol.410, No.3, pp.72-89. 